\title{
Assessment of University Students' attitude towards Fast food consumption Based on the Prototype/Willingness model: A Qualitative Study in the East South of Iran, Rafsanjan
}

\author{
Research Article
}

\section{Seyed Saeed Mazloomy Mahmoodabad ${ }^{1}$, Mahmood Mahbobi Rad ${ }^{*}$, Mohammad Asadpoor ${ }^{3}$, Aliakbar Vaezi ${ }^{4}$, Hossein Fallahzadeh 5 , Hassan Zareei Mahmoodabadi ${ }^{6}$}

1. Professor, Social Determinants of Health Research Center, Department of Health Education \& Promotion, School of Public Health, Shahid Sadoughi University of Medical Sciences, Yazd, Iran.

2. PhD Candidate, Social Determinants of Health Research Center, Department of Health Education \& Promotion, School of Public Health, Shahid Sadoughi University of Medical Sciences, Yazd, Iran.

3. Assistant Professor, Department of Health Services and Promotion, School of Health, Rafsanjan University of Medical Sciences, Rafsanjan, Iran.

4. Department of Nursing Education, Research Center for Nursing and Midwifery Care, Shahid Sadoughi University of Medical Sciences, Yazd, Iran.

5. Professor, Research Center of Prevention and Epidemiology of Non-Communicable Disease, Departments of Biostatistics and Epidemiology, School of Public Health,

Shahid Sadoughi University of Medical Sciences, Yazd, Iran.

6.Department of Education and Psychology, Yazd University, Yazd, Iran.

\begin{abstract}
Background and Purpose: University students are young and are thus at a critical period of adopting healthy behaviors. Their life-style exposes them to a high rate of consuming fast food. In the long run, they are faced with higher chances of obesity and risk of affliction with diabetes and cardiovascular diseases. The present research aims to explore university students' attitude towards fast food consumption based in the Prototype/Willingness model. Materials and methods: The present research followed a qualitative approach and a directed content analysis in 2018-19 among students affiliated with Rafsanjan universities. The participants were selected through purposeful sampling. A semi-structured interview was held with 20 students and it went on until data satiation occurred. The qualitative content analysis was done through Graneheim and Lundman method. Results: Analysis of university students' experience of fast food consumption led to the extraction of 2 categories, 16 sub-categories and 65 final codes. The main theme was attitude for which the following subcategories were extracted: pleasure in consumption, fast preparation, inability to cook, lethargy, low cost, inadequate monitoring, Indulgence, bringing excuses, lack of knowledge, optimism in one's health, consumeristic media, disorganized student life. For the negative attitude category, the following sub-categories were considered: attempts to provide healthy food, hated to fast food
\end{abstract}

Key Words: Attitude, University students, Fast food, Prototype/ willingness model, Qualitative study.

\section{Introduction}

Within the past 30 years, fast food consumption has grown significantly in America and Europe (1). These changes resulted from a change of people's pattern of living and were influenced by advanced

* Corresponding Author:

Mahmood Mahbobi Rad,

$\mathrm{PhD}$ Candidate,

Social Determinants of Health Research Center,

Department of Health Education \& Promotion,

School of Public Health,

Shahid Sadoughi University of Medical Sciences,

Yazd, Iran

Email id-ㅆmahmoodmahbubi@yahoo.com science, industry and life style. Traditional nutritional habits faded away and consuming fast foods grew more than ever before in countries including Iran $(2,3)$. Fast foods are those easily prepared outside one's home (3). Thus, over-consumption of these high-calorie and greasy foods and the imbalance between received and consumed energy would increase the chances of weight gain and affliction with diabetes, cardiovascular diseases and cancers (4). In 2017, on a daily basis, one out of every four Americans ate fast food. Americans showed to have spent more than a hundred billion dollars on fast food (5). In the light of the related literature, the top consumer group of fast foods comprises teenagers and youngsters and about one-third of youngsters consumed ready-made foods on a daily basis $(6,7)$. In Iran, according to the national statistics center report in $2015,47.6 \%$ of the population above 18 
years of age consumed fast food (8). In 2016, the rate of fast food consumption in Iranian teenagers was $20 \%$ (9).

Several reasons have been recognized in the related literature for the high rate of consuming fast foods. These include the change of traditional family structure, better taste, low cost and easy access to such foods $(10,11)$. Fast foods are teenagers' and youngsters' favorite food (12). Thus, preventive programs should focus on youngsters and teenagers (13).

As for high-risk behaviors among youngsters, behavioral models formulate two key hypotheses for decision-making. According to the first hypothesis, the decision-making process for showing a certain behavior follows an analytic trend and takes into account all aspects of an action and does it. According to the second hypothesis, the decision-making process is more subjective and results from subjective images and willingness under certain circumstances. It resembles a social reaction. The above-mentioned hypotheses formed the basis of the Prototype/Willingness model which had in common with the rational action theory such constructs as attitude and social norms. Yet this model enjoyed two new constructs as risk images and beliefs and behavioral willingness. In this model attitude, social norms and initial belief are factors that directly affect behavioral willingness (14). Attitude is the first determining factor of behavioral intention and refers to the desirability or undesirability of a behavior as perceived by an individual. Attitude results from one's positive and negative beliefs in a behavior (15).

There is a dearth of research into Iranian university students' perceptions, beliefs and attitudes toward fast food consumption. Considering the significance of university students' attitude and experiences in decision-making and implementation of preventive programs and due to the fact that many experiences, perceptions and beliefs are not quantifiable, it is essential to investigate such matters appropriately. Qualitative research methods provide for an objective description and deep understanding of phenomena and human experiences (16). There seemed to be a variety of ideas about fast food consumption among university students, which are not recognized yet. Thus, in order to access different overt and covert aspects of students' attitude, some qualitative research was required to explore their real perception of experiences. Their needs should be analyzed to develop an appropriate educational plan. Thus, the present research aimed to explore students' attitude toward fast food consumption based on the Prototype/Willingness model in the universities of Rafsanjan County.

\section{Material and Methods}

The present qualitative research followed a directed content analysis approach based on the Prototype/Willingness model on 20 participants affiliated with the universities of Rafsanjan (east south of Iran). The interviews were conducted between November 2018 and April 2019 with a sample selected through purposive sampling. It was made sure to include a maximum variety of age, gender and place of residence. In this research, the Prototype/Willingness model and the attitude construct were used to explore university students' perceptions and experiences. The interviews were held face to face using a semistructured interview based on the attitude construct of the Prototype/Willingness model. The inclusion criteria were passing at least 2 academic semesters and full consent to take part in the research.

Before any interview, the purpose of research and why it was needed to record voices were explained to the participants. It was made sure that they trusted the researchers and willingly and voluntarily participated in this research. Participants' consent and respect for their ethical rights were approved by Shahid Sadoughi University of medical sciences (ethical code: IR.SSU.SPH.REC.1398.012). To analyze the data, the qualitative content analysis proposed by Graneheim and Lundman was used. To this aim, the recorded interviews were reviewed several times and were precisely transcribed. Subsequently, while the transcripts were revisited, the content was summarized into meaning units and turned into codes in the following stage. Then, the codes were cross-compared in terms of similarities and differences and the categorization and subcategorization were done. The interviewed continued until data satiation occurred. In the last two interviews, no new code was extracted (17). For data accuracy and consistency, Cuba and Lincoln's criteria were used including credibility, transferability, dependability and conformability (18). In the present research, to increase the credibility of data analysis, the data coding and review of coding were done by the present researchers. Moreover, researcher's longitudinal involvement in the research was used to attract university students' trust. To enhance dependability, participants' exact quotations were used. External check was used to increase conformability.

\section{Results}

The mean age of the participants was $25 \pm 2.5$ years. Table 1 indicates participants' demographic information.

\section{Table 1: Research participants' demographic} information

\begin{tabular}{|c|c|c|}
\hline Variable & Condition & F (\%) \\
\hline \multirow{2}{*}{ Age } & 20-25 yrs. & $12(60)$ \\
\hline & $25-30$ yrs. & $8(40)$ \\
\hline \multirow{2}{*}{ Gender } & Male & $13(65)$ \\
\hline \multirow{2}{*}{ Marital status } & Female & $7(35)$ \\
\hline Place of & married & $15(75)$ \\
\hline residence & Single & $5(25)$ \\
\hline & Dormitory & $10(50)$ \\
\hline & Rented house & $6(30)$ \\
\hline & Own house & $4(20)$ \\
\hline
\end{tabular}

Analysis of university students' commentaries led to the extraction of 2 categories, 16 sub-categories and 65 final codes. The main theme was attitude. For 
positive attitude, the sub-categories were pleasure in consumption, fast preparation, inability to cook, lethargy, low cost, inadequate monitoring, Indulgence, bringing excuses, lack of knowledge, optimism in one's health, consumeristic media, disorganized student life. The sub-categories of negative attitude were attempts to provide healthy food, hatred, creation of a healthy supportive family life, bad experiences, perceived threat and perceived consequences. How the codes, categories, sub-categories and theme were formed is reported in Tables 2, 3 and 4 .

\section{Table 2: Coding procedure of meaning units}

Abstracted meaning unit Code

Choice of fast food due Fast preparation of fast to fast preparation food

\section{Table 3: Sub-categorization of codes}

Sub-category Code

Fast preparation of food Ease access to fast food Fast preparation of fast

food

Limited time for cooking

Table 4: Categorization and sub-categorization process

\begin{tabular}{|c|c|c|}
\hline \multirow{19}{*}{$\begin{array}{l}\text { Theme } \\
\text { Attitude }\end{array}$} & Category & Sub-category \\
\hline & \multirow{12}{*}{$\begin{array}{l}\text { Positive } \\
\text { attitude }\end{array}$} & Pleasure in consumption \\
\hline & & Fast preparation of food \\
\hline & & Inability to cook \\
\hline & & Lethargy \\
\hline & & Low cost \\
\hline & & Inadequate monitoring \\
\hline & & Indulgence \\
\hline & & Bringing excuses \\
\hline & & Lack of knowledge \\
\hline & & Optimism in one's health \\
\hline & & Consumeristic media \\
\hline & & Disorganized student life \\
\hline & \multirow[t]{6}{*}{$\begin{array}{l}\text { Negative } \\
\text { attitude }\end{array}$} & $\begin{array}{l}\text { Attempts to provide healthy } \\
\text { food }\end{array}$ \\
\hline & & $\begin{array}{l}\text { Hated to fas t food } \\
\text { consumption }\end{array}$ \\
\hline & & $\begin{array}{l}\text { Creation of a heathy } \\
\text { supportive family } \\
\text { atmosphere }\end{array}$ \\
\hline & & Bad experiences \\
\hline & & Perceived threat \\
\hline & & Perceived consequences \\
\hline
\end{tabular}

Sub-categories of the positive attitude category: Pleasure in consumption:

A number of participants believed that the pleasure they find in consuming fast food and its spicy content cannot be found in any traditional food.

"I take special pleasure in eating sandwich and pizza. It gives me a great joy especially with lots of sauce and coke". (\#3, male)

\section{Fast preparation}

Some comments made by the participants indicated that a main cause of overconsuming fast food is the ease of preparing it which encourages more consumption of this type of food.

"Fast food is always my choice as it is readily prepared and one can have time for the rest of the day". (\#2, male)

\section{Low cost}

As several participants recalled, a key factor in fast food consumption is the high cost of traditional food and the required ingredients for a healthy cooking.

With this respect, a participant maintained: "Students look for cheap food such as Falafel or Bandari sandwiches which are much cheaper than rice" (\#7, female)

\section{Inadequate monitoring}

A number of comments showed that one factor strongly influencing fast food consumption is lack of family control during student life.

"After entering university, students find themselves unwatched by parents. So, they begin to consume more fast food" (\#11, male)

\section{Inability to cook}

Another factor mentioned by a number of participants for consuming fast food was their inability to cook healthy food.

"I have never cooked. I'm not interested in cooking at all". (\#16, female)

\section{Lethargy}

As pinpointed by a number of participants, lethargy was a key factor involved in university students' consuming fast foods as they were lazy to cook healthy food.

"University life makes us lazy. Students are mostly engaged with their laptop computer and mobile phone. They waste time in virtual world". (\#9, male)

Disorganized student's life:

Another factor raised by several participants as a reason for the prevalence of fast food consumption was the disorganized life of university students.

"The sort of problems in university students' life would impede a proper diet". (\#2, male)

\section{Indulgence}

As the comments made by several participants showed, an influential factor involved in consuming more and more fast food was students' indulgence in and having fun with peers. female)

"Eating fast food with friends is fun". (\#12,

\section{Bringing excuses}

Several participants attempted to bring different excuses for consuming fast food.

"I have just heard that fast food damages health but it is not proven to me. Maybe as it hurts in the long run, for example above 40 years of age". (\#13, male) 
Inadequate knowledge

Another point raised by some participants was their lack of knowledge of the adverse effects of fast food and healthy alternatives to fast food.

"Now, my friends and I cannot tell exactly what negative effects pizza produces on us". (\#8, male)

\section{Optimism in one's health}

The majority of participants believed that because they were young and strong, despite consuming fast food, they would not become sick.

"The youth think as they are young and sportive, fast food cannot harm their health". (\#4, male)

\section{Consumeristic media}

Several comments indicated that media effectively stimulated fast food consumption.

"Now the case is that on virtual pages, celebrities advertise fast food. I myself found a good fast food restaurant through Instagram". (\#14, female) Subcategories of negative attitude category:

\section{Attempts to provide healthy food}

A number of participants believed they were truly interested in healthy food and they made every effort to provide healthy food.

"I am really into preparing healthy home-made fast food sometimes using natural ingredients". (\#12, female)

\section{Hated to fast food consumption}

A few participants admitted that they generally hated to eat fast food.

"I have seen friends having a voracious appetite for fast food. Yet, I hate to eat fast food". (\#1, female)

\section{Creation of a heathy supportive family atmosphere}

As a number of participants believed, family background and the support of family members play a main role in developing the habit of preparing and consuming healthy food.

"As my mother is a housewife, we regularly eat home-made food". ( $\# 5$, female)

\section{Bad experience}

As pinpointed by several participants, overall bad experiences of fast food consumption would lead to the avoidance of the food totally.

"I don't eat fast food as I got food poisoning once". (\#6, male)

\section{Perceived threat}

As a number of participants quoted, fast food consumption for sure led to a disease. Thus, fast food consumption was to be avoided at all costs.

"In my opinion, fast food is harmful and can cause heart diseases". (\#10, female)

\section{Perceived consequences}

As pinpointed by a number of participants, the adverse effects of fast food were observable in them, their family or friends.
"I used to be really fat. Sometimes, I suffered from stomachache, backache or else. At home, my father had both diabetes and hypertension which ran through the family. Thus, I felt the threat and began to lose weight". (\#18, male)

\section{Discussion}

The present research is the first qualitative study which explores university students' attitude towards fast food consumption in Iran. For the positive attitude category, the following sub-categories were perceivable: pleasure in consumption, fast preparation, inability to cook, lethargy, low cost, inadequate monitoring, Indulgence, bringing excuses, lack of knowledge, optimism in one's health, consumeristic media, disorganized student life. For the negative attitude category, the following sub-categories were considered: attempts to provide healthy food, hated to fast food consumption, creation of a healthy supportive atmosphere by the family, bad experiences, perceived threat and perceived consequences. In Avram and Oravitan study, 3 main reasons for consuming unhealthy food as perceived by Romanian students were limited time, inadequate knowledge and inadequate money (26). These were matched with the fast preparation, low cost and inadequate knowledge subcategories in the present research. These indicated the underlying factors of willingness to consume fast food among university students and needed to be considered in healthcare planning. In their research, Amanda et al. (2010) drew attention to 3 key factors involved in the choice of Irish teenagers' food: 1. Personal factors: correlation of dietary preferences and awareness of healthy food, 2. Within-family factors: the effect of eating habits within one's family, 3. Outer-family factors: effect of when the food was prepared and served outside one's own home. Researchers concluded that no control of teenagers' dietary habits by parents has increased fast food consumption in them (20). The findings of this last research were consistent with the inadequate monitoring subcategory of the present research. It further shows that the loss of dietary control of university students by parents would form unhealthy dietary behaviors and willingness to consume fast food in them. These are to be educated gradually before admission to university so as to guarantee a better control of nutritional behaviors. In their research, Deliens et al. (2014) explored factors affecting a healthy dietary behavior in Belgian university students. These include personal factors (food taste, convenience, time, self-control), social network factors (lack of control by parents, friends and peers), physical environment (access to different food types, food costs) and social factors (media and advertisement). Moreover, university-related factors and student life style as well as exam stress were also involved (21). These findings were consistent with these subcategories: pleasure in consumption, fast preparation, low cost, inadequate monitoring, indulgence, consumeristic media and disorganized student life style. It seems that planning educational interventions for students should be done at multiple levels and across different social sections 
including family, university and mass media coordinated between and among authorities. The aim is to evidence the promotion of university students' health state.

In The work of research by Askari Majdabadi et al. (2016) concerning the strategies of reducing fast food consumption as perceived by parents and teenagers' nutritionists, three categories of factors were identified, personal, social and familial. As for the familial category, creating a healthy dietary environment by the family was one of the main subcategories introduced (22). This is in line with the creation of a healthy supportive family life sub-category in the present research. This would indicate that family has a key role in encouraging teenagers and youths to consume healthy food and develop negative attitude to fast food consumption. This needs to be educated to parents through mass media especially to mothers who play a key role in providing and offering healthy food to youngsters. In their research, Murimi et al. (2016), explored the effective factors in the choice of food by students in Louisiana State of the U.S. which showed that such factors as perceived food taste, appearance, name, cultural preferences and safety are among factors affecting the food choice and need to be considered in order to promote healthy foods (23). This is consistent with the sub-categories of pleasure in consumption (positive attitude) and perceived threat (negative attitude) in our research. It is evident that although a good taste of fast foods is a factor involved in one's willingness to consume them, perceiving the possible threats to health that can accompany them can develop a negative attitude and prevent fast food consumption. Thus, educating youngsters especially teenagers and raising their awareness of fast food threats can help to decrease the willingness to consume fast food.

The strength of the present research lies in the choice of participants of maximum variety (gender, age and place of residence) which seems to cover an adequate width of coverage. The limitation of the present research was the lack of panel discussion for data collection due to time pressure. It is suggested that further research use a combination of methods for data collection (personal interview and panel discussion).

\section{Conclusion}

In the light of the positive and negative categories extracted, the present researchers make several recommendations to promote healthy nutrition among university students: raising awareness of the choice of healthy foods and how they are prepared, increasing self-control, developing time management, increasing social support, creating a healthy supportive environment in family, developing a supportive environment at university e.g. provision of cheap healthy food, educating university students on healthy nutrition by authorities, mass media support to propagate behaviors concerning healthy nutrition. It seems that awareness of positive and negative attitudes can help policy makers to employ the best preventive strategy with a focus on adjusting positive attitudes and promoting negative attitudes towards fast food consumption.

\section{Acknowledgements}

The present authors wish to express gratitude to all participating university students in this research. The present research is derived from a Ph.D. dissertation of health education and promotion approved by Shahid Sadoughi University of medical sciences in Yazd (registration code : IR.SSU.SPH.REC.1398.012). The gratitude is extended to the deputy of research at the health faculty of Shahid Sadoughi University of medical sciences in Yazd for their financial support. There is no conflict of interests to declare.

\section{References}

1. Yarmohammadi p Sharifirad GR, Azadbakht L, Morowati SMA, Hassanzadeh A. Determinants of Fast Food Consumption among Iranian High School Students Based on Planned Behavior Theory . Journal of Obesity. 2013 Volume, 147589, 7 pages [Persian]

2. Dadipoor S, Madani A, Ghanbarnejad A, Safari Moradabadi A, Amani F, Hosseini M, \& Yeganeh H. Effective factors related to fastfoods consumption in Bandar Abbas: A community-based study. Journal of Health Education and Health Promotion 2014;2(2): 77-86. [Persian]

3. Fazelpour S, Baghianimoghadam M, Nagharzadeh A, Fallahzadeh H, Shamsi F, Khabiri F. Assessment of fast food concumption among people of yazd city. Toloo-e-Behdasht. 2011;10(2):25-34. [Persian]

4. James J, Kerr D. Prevention of childhood obesity by reducing soft drinks. Int J Obesity. 2005;29:S54-S

5. https://brandongaille.com/27-fast-foodconsumption-statistics-america/ dated.5-2017 time 10:20 IST

6. Bowman SA, Gortmaker SL, Ebbeling CB, Pereira MA, Ludwig DS. Effects of fast-food consumption on energy intake and diet quality among children in a national household survey. Pediatrics. 2004;113(1):112-8

7. Paeratakul S, Ferdinand DP, Champagne CM, Ryan DH, Bray GA. Fast-food consumption among US adults and children: dietary and nutrient intake profile. J Am Diet Assoc. 2003;103(10):1332-8. .

8. https://www.amar.org.ir/ dated.3 -2017 time 11:36 IST

9. Kelishadi R, Mozafarian N, Qorbani M, et al. Association between screen time and snack consumption in children and adolescents: The CASPIAN-IV study. J Pediatr Endocrinol Metabolism 2017;30:211-9.

10. Pereira MA, Kartashov AI, Ebbeling CB, et al. Fastfood habits, weight gain, and insulin resistance (the CARDI Astudy): 15-year prospective analysis. Lancet 2005;365:36-42

11. Driskell JA,Meckna BR,Scales NE.Differences exist in the eating habits of university men and women at fast-food restaurants.nutrition Research.2006;26(10):1960-4 
12. Paeratakul S,Ferdinand DP,Champagne CM,Ryan DH,Bray GA.Fast-food consumption journal of the American Dietetic .among US adult and children: dietary and nutrient intake profile.Association.2003;103(10):1332-8

13. Ghaffari M, Niknami Sh, Kazemnejad A, Mir-zae E, Ghofranipour F. Designing and validat-ing 10 conc eptual scales to prevent HIV among adolescents. Behbood J. 2007; 11: 38-49[Persia

14. Blanton H, Gibbons FX, Gerrard M, Conger KJ, Smith GE. role of family and peers in the development of prototypes associated with substance use. J Fam Psychol. 1997; 11: 271-88.

15. Ajzen I. Theory of planned behavior. Handb Theor Soc Psychol Vol One. 2011;1:438.

16. Shariati M, Dadghari A. Design and application and analysis of qualitative research in the field of health and medical science. Tehran: Hayan Publication. 2007

17. Graneheim UH, Lundman B. Qualitative Content Analysis In Nursing Research: Concepts, Procedures And Measures To Achieve Trustworthiness. Nurse Educ Today 2004; 1;24:105-12.

18. Vicent N A. Ensuring The Quality of The Findings Of Qualitative Research: Looking At
Trustworthiness Criteria. JETERAPS 2014;5:272-281. 18-

19. AVRAM C, ORAVITAN M. Fruit, Vegatables and Fast Food Consumption among University Students. Timisoara Physical Education and Rehabilitation Journal. 2013;5(10)

20. Amanda Fitzgerald, Caroline Heary, Elizabeth Nixon, Colette Kelly; Factors influencing the food choices of Irish children and adolescents: a qualitative investigation, Health Promotion International, 2010; 25(3), Pages 289-298

21. Deliens et al.: Determinants of eating behaviour in university students: a qualitative study using focus group discussions. BMC Public Health 2014 14:53.

22. Askari Majdabadi H, Montazeri A, Shojaeizadeh D, Nedjat S, Khalajabadi Farahani F, et al. Parents' and Stakeholders' Perspectives on Strategies to Reduce Fast Food Consumption Among Iranian Adolescents: A Qualitative Study, Iran Red Crescent Med J. 2017 ; 19(1):e58853.

23. Murimi MW, Chrisman M, McCollum HR, Mcdonald O. A Qualitative Study on Factors that Influence Students' Food Choices. J Nutri Health. 2016;2(1): 6 . 